\title{
Traducción y censura: algunas notas
}

Flora BOTTON-BURLÁ Universidad Nacional Autónoma de México

Generalmente, cuando hablamos de problemas de traducción, nos referimos en primer lugar a fenómenos que son sobre todo de tipo lingüístico. Pero es bien sabido que en asuntos de traducción, al igual que en otras cueștiones literarias en general, intervienen elementos de muchos otros tipos, entre los que ocupan un lugar no poco importante los que se podrían llamar "culturales".

Una de estas cuestiones culturales es la de la censura. Cuando se habla de censura, se entiende generalmente el derecho que se adjudican o se han adjudicado los gobiernos de ejercer una vigilancia sobre las publicaciones de todo tipo. Sin embargo, hay múltiples ocasiones en que la censura, a la que Benjamin Constant llamó "insolente violación de nuestros derechos, sujeción de la parte ilustrada de la nación a su parte estúpida y vil, gobierno de los mudos",' no necesita de la autoridad pública para ejercerse.

Uno de estos casos se da en la traducción. Aunque la mayoría de los traductores tiene un gran respeto por su trabajo (o por 10 menos eso queremos creer), muchas veces nos encontramos con que el traductor, de manera nada inconsciente, sino todo lo contrario, ha aportado modificaciones al texto fuente $-y$ modificaciones que a veces pueden ser muy importantes - en aras de un código extralingüístico que, en ese momento, tiene la primacia sobre la fidelidad debida al texto que se traduce. Intervienen así, aparte de las consideraciones lingüisticas, argumentos de tipo ideológico, que igualmente pueden ser políticos que morales, o de cualquier otra clase. El traductor, pues, interviene - fuera del código estrictamente lingüístico- para hacer transformaciones (o buscar equivalencias) que se inscriben en el código cultural.

Quiero ocuparme aqui de uno de estos casos de modificación, o más bien dicho, de censura ejercida por un traductor (que por lo demás, a no

\footnotetext{
'Apud Encyclopaedia Universalis. París, 1983, t. 4, p. 486, s.v. 'censure'.
} 
ser por este pequeño "detalle", es una persona cuidadosa y consciente). En 1880, Juan Valera publica en España (Madrid o Sevilla, según las fuentes) su traducción de una preciosa novelita griega del siglo II o III de nuestra era: Dafnis y Cloe, de Longo. ${ }^{2}$ Las razones de Valera para emprender esta traducción son bien claras: en primer lugar, le gustan los clásicos, y cree que deberían ser mejor conocidos de lo que son. En segundo lugar, le parece que hay más posibilidades de que agrade "al vulgo" un texto en prosa que uno en verso. Los hexámetros antiguos no pasan bien al español, y ésa puede ser una de las razones por las que no gustan. Dafnis y Cloe, en cambio, tiene la ventaja de estar escrita en prosa. Además, la novela es "un género más de moda hoy que nunca", y, en opinión de Valera, Dafnis y Cloe es "la mejor que se escribió en la antigüedad clásica". 3

Esta novela, sigue diciendo Valera, "está traducida en casi todos o en todos los idiomas modernos", y es hora de que lo esté en español, en "una traducción fiel y hecha con alguna gracia". ${ }^{4}$ Además, encuentra que hay sobradas razones para que guste a los lectores modernos: es concisa, está escrita en un estilo sencillo, hay en ella una pintura viva de la naturaleza. Pero más que nada, evidentemente la razón principal es que a Valera le encanta Dafnis y Cloe (repite por lo menos tres veces que es "la mejor" de las novelas griegas).

Sin embargo, el texto tiene, para Valera, un gran defecto, que será preciso subsanar. Cito, de la "Introducción":

Una gran contra, fuerza es confesarlo, tiene, por cierto, Dafnis y Cloe: el realismo de sus escenas amorosas, la libertad, que raya en licencia, con que algunas están escritas; pero sirva de disculpa que lo que en Dafnis y Cloe pueda tildarse de licencioso no es en el fondo perverso, $y$ si algo de esto último hay en el original, lo hemos cambiado o suprimido. ${ }^{5}$

Lo que llama poderosamente la atención en este pasaje es la tranquilidad con que el traductor habla de cambios o supresiones. $Y$ éstos, por cierto, no son pocos, pues afectan a una buena parte del último libro, el IV.

\footnotetext{
${ }^{2}$ He podido encontrar dos ediciones diferentes de esta traducción de Valera, publicadas respectivamente en México (1940) y en Buenos Aires (1943); esta última es la que cito en el texto. Para los datos completos, véase la bibliografia.

${ }^{3}$ Juan VALERA, "Introducción", en LoNGo, Dafnis y Cloe, p. 5.

${ }^{4}$ Idem.

${ }^{5}$ Ibid., p. 7. Los subrayados, en este caso y en los demás, son míos.
} 
Valera aclara algo, pero no mucho, en la primera nota que pone a su traducción: "en nuestra traducción de los tres primeros libros hemos procurado ser tan fieles al original como es posible en una lengua moderna de Europa". ${ }^{6}$

$Y$ su texto es, en efecto, fiel al original, con la salvedad de algunos detalles mínimos que no vale la pena comentar aquí. Pero las cosas no son $\tan$ sencillas. Volvamos a la nota:

En el cuarto libro nos hemos atrevido a hacer bastantes alteraciones: algo parecido a lo que llaman un arreglo. Esto no quita que muchos párrafos [más de la mitad de dicho libro cuarto] estén también traducidos por nosotros con la mayor exactitud. Sólo hemos variado unos lances originados por cierta pasión repugnante para nuestras costumbres, sustituyéndolos con otros fundados en más naturales sentimientos. ${ }^{?}$

Tanto circunloquio, tanto eufemismo no pueden dejar de ser misteriosos, y de despertar la curiosidad del más letárgico de los lectores. La honestidad fundamental, a pesar de todo, del traductor le resulta contraproducente. Imagino que no hay lector, por apático o desinteresado que sea, que no se pregunte de qué se trata, y cuál es esa "pasión repugnante para nuestras costumbres". El efecto es que el episodio de homosexualidad del libro IV pasa a tener una enorme importancia y quizás sea lo que más se recuerda de la traducción de don Juan Valera, que bien merecía mejor suerte, pues su texto es realmente delicioso y ha logrado reproducir con gran acierto el tono de la novela.

Valera se convierte, pues, de traductor en censor, y hace "lo que llaman un arreglo". A fin de poder ver en qué consiste, propongo comparar su traducción (que por cierto es la primera que se hace al español) con otra, mucho más reciente, obra de Lourdes Rojas Álvarez. ${ }^{8}$

${ }^{6}$ Ibid., p. 84.

${ }^{7}$ Idem.

${ }^{8}$ LONGo, Pastorales de Dafnis y Cloe. México, UNAM, 1981. Como elementos adicionales de comparación (puesto que mi manejo del griego, y sobre todo del griego clásico, es extremadamente limitado), uso tres traducciones al francés: la de Amyot, refundida por Courier, la de Dalmeyda y la de Vieillefond (que, hasta donde yo sé, es la más reciente); por último, be consultado también la versión inglesa de Thornley, revisada y aumentada por Edmonds y publicada en la "Loeb Classical Library". Quede claro que mi análisis no es de los puntos finos de la traducción, para lo cual evidentemente es indispensable manejar el texto original, sino que se refiere tan sólo a la censura del contenido del texto y de sus valores, que es el tema de este trabajo. 
En el libro IV de Dafnis y Cloe aparece un personaje, el parásito Gnatón, que se enamora perdidamente de Dafnis, el hermoso pastor. Veamos el texto de Lourdes Rojas:

Por su parte Gnatón, como hombre que sabia comer y beber hasta emborracharse y tener tratos intimos después de la borrachera y, no siendo otra cosa que cachete y vientre y lo que está debajo del vientre, no vio superficialmente a Dafnis cuando llevaba los regalos, sino que siendo pederasta por naturaleza, y encontrando una hermosura como no habia encontrado en la ciudad, resolvió procurarse a Dafnis y pensó que, como era cabrerizo, lo persuadiría fácilmente. $\mathrm{Y}$ habiendo decidido esto, no acompañó a Astilo a cazar, sino que, bajando a donde Dafnis pastoreaba, con el pretexto de las cabras, en verdad fue a ver a Dafnis. Y lisonjeándolo, ensalzó las cabras y le rogó que tocara en la siringa un son de cabrero, y le dijo que rápidamente lo iba a poner libre, pues lo podia todo. ${ }^{9}$

(IV, XI, 2-3)

Y ahora, la versión de Valera:

Gnatón, por el contrario, no hallaba placer sino en la comida y en beber hasta emborracharse: era como un sumidero, todo gula y todo lascivia y pereza. Así fue que no quiso ir a cazar con Astilo, y para entretener el tiempo, bajó hacia la playa, donde se encontró a Dafnis guardando su ganado. Junto a Dafnis estaba Cloe, hermosa como nunca. La vio Gnatón, y quedó al punto prendado de ella. Pensó que en la ciudad no habia visto jamás más linda moza. Dafnis, a quien apenas apuntaba el bozo, y que parecia más niño y más dulce aún de lo que era, no infundió el menor respeto al parásito. Y como la zagala era sencilla y humilde, juzgó fácil empresa deslumbrarla y lograrla. ${ }^{10}$

Así pues, el amor homosexual se ha trocado, gracias a la magia del "arreglo", en pasión heterosexual. El pederasta de Longo ha desaparecido por completo. Gnatón es ahora, "simplemente", un libertino (y es obvio que ese libertinaje resulta, para Valera y para su época, mucho más aceptable que la "pasión repugnante"). Fuerza es reconocer que el traductor se esforzó en mantener ciertos temas que aparecen en el texto original, como la comparación campo/ciudad (o sea, del pastor/la pastora con sus posibles equivalentes en la ciudad). Pero los términos directos

9 Vers. de Lourdes Rojas, ed. cit., p. 67.

10 Vers. de J. Valera, ed. cit., p. 68. 
que emplea Longo son sustituidos por eufemismos, o simplemente eliminados: el "cachete y vientre y lo que está debajo del vientre" se convierte en "gula, lascivia y pereza". Se introduce además un tema nuevo: Dafnis no vale como posible defensor de Cloe, puesto que es muy joven y no inspira "el menor respeto". La dulzura de Dafnis, sin embargo, si aparece en el original, aunque un poco más adelante. Para aclarar esto, volvamos al texto de Lourdes Rojas:

Y como vio que era de carácter dulce, emboscándose de noche, cuando de regreso de la pastura llevaba sus cabras, corriendo hacia él lo besó primero, luego le pidió que se le ofreciera por detrás, tal como las cabras a los cabríos. Y como Dafnis comprendiera lentamente, y dijera que estaba bien que los machos montaran a las cabras, pero nunca alguien había visto a un macho montando a un macho, ni a un morueco un morueco en vez de a las ovejas; ni a gallos, gallos en vez de a gallinas, Gnatón estaba pronto a usar la violencia poniéndole las manos encima. ${ }^{11}$

(IV, XII, 1-2)

Por razones obvias, este pasaje ha sido suprimido en el texto de Valera. Sigamos con la versión de Lourdes Rojas:

Entonces él [Dafnis], rechazando al borracho que apenas se estaba de pie, lo derribó al suelo, y como un cachorro se alejó corriendo y lo dejó tirado, necesitado de un hombre, no de un niño, para llevarlo de la mano. Y ya no se le acercaba para nada, sino que unas veces pastoreaba las cabras en una parte y otras en otra, huyendo de él, y tenía a Cloe bajo su cuidado. Ni Gnatón se esforzaba ya, reconociendo además que no sólo era hermoso sino también fuerte. Pero buscaba el momento oportuno para hablar sobre él a Astilo, y esperaba obtenerlo como regalo de parte del joven que quería concederle muchas y grandes cosas. $^{12}$

(IV, XII, 3-4)

Si vemos ahora el texto de Valera y la seducción de Cloe, que no de Dafnis, leemos:

A este fin empezó por elogiar sus ovejas; luego la elogió a ella; luego trató de alejar a Dafnis y no pudo conseguirlo y, por último, movido

$"$ Vers. de L. RoJAs, ed. cit., p. 68.

12 Idem. 
de una pasión que a los más cuerdos roba la prudencia, tomó a Cloe entre sus brazos y la besó repetidas veces, aunque ella se resistía. Dafnis acudió a interponerse, y se interpuso entre ambos cuando Gnatón quería renovar los besos, haciendo poca cuenta de quien se le oponía, y creyéndole débil, o tan respetuoso que el respeto le ataría las manos. Por dicha, no fue así: Dafnis rechazó a Gnatón con tremendo brio, y como Gnatón, según su costumbre, estaba borracho y poco firme sobre sus piernas, dio consigo en el suelo cuan largo era, donde Dafnis [८o Valera?], ciego de cólera, le pateó a su sabor y con alguna saña. Viendo después que el vencido y pateado no bullía, Dafnis tuvo miedo de su proeza y echó a huir, seguido de Cloe, dejando el hato en abandono.

Con la afrenta y el dolor se le disiparon a Gnatón los vapores del vino; calculó que era muy ridículo quejarse y contar lo que había ocurrido, y determinó callárselo; pero más empeñado que antes en conseguir su propósito, resolvió pedir a Astilo, que nada le negaba, que se llevase a Dafnis a la ciudad y quedase él luego algún tiempo en aquel campo, donde ya sin estorbo podría lograr a Cloe. ${ }^{13}$

Aquí, aparte del cambio básico, encontramos unos elementos añadidos que son de lo más curioso: resulta que Gnatón no hace caso de Dafnis como defensor porque cree que el respeto le atará las manos. Ese respeto, que sólo puedo atribuir a que Valera piense en diferencia de clase social, es algo que ciertamente no aparece, o no en esta forma, en la novela de Longo. Por otra parte, la cólera de Dafnis está tan fuera de su carácter que uno no puede evitar preguntarse quién es el que realmente propina la paliza a Gnatón: Dafnis, o el propio Valera, que expresa así su indignación, escudándose tras la figura del pastor. En Efecto, el comportamiento de Dafnis ha sido totalmente distinto: en otras ocasiones en que se ha presentado un rival para el amor de Cloe, la reacción de Dafnis es más bien de desesperación y llanto, no de ira. Las patadas, y sobre todo la saña con que se dan, no han sido características de Dafnis en ningún momento de la novela. Y el dejar solos a los animales que tiene a su cuidado es precisamente lo que Dafnis y Cloe nunca hacen. En cuanto a la resolución de Gnatón de no hacer el ridículo relatando el incidente, no puedo evitar pensar que ésta es una enmienda que a Valera de todos modos le hubiera gustado hacer en el texto, con o sin homosexualidad de por medio.

Hay otros "acomodos" en este pasaje, y valdría la pena examinar con detenimiento tan siquiera algunos de ellos. Sin embargo, en aras de la

${ }^{13}$ Vers. de J. VALERA, ed. cit., pp. 68-69. 
brevedad, me limitaré a una última nota: cuando Gnatón (en el original, se entiende) le pide a Astilo que le dé a Dafnis para llevárselo consigo a la ciudad, el joven le pregunta burlonamente si no se avergüenza de amar a un burdo pastor, que seguramente apesta a cabra. Gnatón le contesta:

Y si estoy enamorado de un pastor, recuerda a los dioses. Boyero era Anquises, y Afrodita lo tuvo. Branco pastoreaba cabras, y Apolo lo amó; pastor era Ganimedes, y lo raptó el rey de todas las cosas. No desdeñemos a un niño a quien vimos que también las cabras obedecen como enamoradas. Y si aún dejan que se quede en la tierra tal belleza, demos gracias a las águilas de Zeus. ${ }^{14}$

(IV, XVII, 6-7)

Valera, obligado por su fábula, se ve forzado a modificar también los ejemplos mitológicos. Astilo le pregunta a Gnatón cómo puede "acostarse con una zagala que por fuerza había de oler pícaramente", y éste responde:

En esto de amar a las pastoras y gente del campo, ¿qué hago yo más que imitar a las deidades? Vaquero fue Anquises, y Venus le tomó por querido. Pitis, amada de Pan y de Bóreas, y Maya misma, tan amada de Júpiter, ¿eran al cabo más que pastoras? No menospreciemos a Cloe porque lo es, sino demos las gracias a los dioses de que, enamorados de ella, no nos la roban y se la llevan al cielo. ${ }^{15}$

Sin duda es triste que la versión de don Juan Valera, a todas luces llena de cualidades en cuanto a su manejo de la lengua, a la fluidez y la elegancia con que rinde los matices de la novela griega, desmerezca en el último análisis por la imposición forzada de un sistema de valores diferente, que equivale a una falta de respeto grave por el texto original. Los lectores actuales nos vemos obligados —quizá a pesar nuestro-a dar también gracias a los dioses, pero por el hecho de que, según parece, los traductores contemporáneos trabajan con la convicción de que una de sus obligaciones primordiales es no enmendar el original, y de que tienen el deber de no convertirse en censores morales o políticos, sino en intérpretes fieles de sus escritores predilectos.

14 Vers. de L. RoJAs, ed. cit., p. 71.

15 Vers. de J. VALERA, ed. cit., p. 71. 


\section{Bibliografia}

Hermans, Theo, "Introduction", en Theo Hermans, ed., The Manipulation of Literature. Londres/Sydney, Croom Helm, 1985.

Longo, Dafnis y Cloe. [S. nom. de trad.] Buenos Aires, Anaconda, 1943.

Longo, Dafnis y Cloe. Trad. de Juan Valera. México, Compañía General Editora, 1940. (Mirasol)

Longo, "Dafnis y Cloe", en Cuatro novelas de amor. Trad. de Juan Valera. Buenos Aires, W. M. Jackson, Inc., 1943.

Longo, Pastorales de Dafnis y Cloe. Introd., vers. y notas de Lourdes Rojas Álvarez. México, UNAM, 1981. (Bibliotheca scriptorum graecorum et romanorum mexicana)

Longus, Daphnis et Chloé. [S. nom. de trad.] París, Flammarion, 1892.

"Les pastorales de Longus ou Dafnis et Chloé", en Les romans grecs. Trad. al fran. de A. J. Amyot, refund. por Paul-Louis Courier. Est. prelim. de A. Chassang. París, Garnier, [s. a.]

Longus, Pastorales (Daphnis et Chloé). Establ. del texto y trad. al fran. de Georges Dalmeyda. París, Société d'Édition "Les Belles Lettres", 1934.

Longus, Pastorales (Daphnis et Chloé). Establ. del texto y trad. de JeanRené Vieillefond. París, Société d'Édition "Les Belles Lettres", 1987.

Longus, Daphnis \& Chloe. Trad. al ing. de George Thornley [1657], rev. y aum. por J. M. Edmonds [1916]. Cambridge/Londres, Universidad de Harvard/William Heinemann Ltd, 1978. (Loeb Classical Library) 